\title{
Sleep Quality and Its Health Correlates Among Egyptian Secondary School Students
}

\author{
Dalia M. Ismail \\ Assiut University \\ Dalia G. Mahran \\ Assiut University \\ Ali H. Zarzour \\ Assiut University \\ Ghaydaa A. Sheahata \\ Assiut University Hospitals, Assiut University
}

The objective of the present study was to determine the prevalence of poor sleep quality and to assess its psychological and general health correlates among secondary school students in the city of Assiut, Egypt. A cross sectional study was conducted among 829 secondary school students (selected by multistage stratified random sampling) aged 15-19 years in Assiut. Students filled in a self-administered questionnaire that included demographic data, Pittsburgh Sleep Quality Index (PSQI), Epworth Sleepiness Scale, general perception of health, and the short form of Depression Anxiety and Stress Scale. The prevalence of poor sleep quality (PSQI $>5$ ) was $72.5 \%$. The mean PSQI score was $7.35 \pm 2.94$ standard deviation. Poor sleep quality was higher among females, urban residents and public school students. Correlates of poor sleep by multivariate analysis were age, urban residence, public education, mild to moderate and severe to very severe anxiety symptoms, severe to very severe depressive symptoms, excessive daytime sleepiness, and feeling fully active sometimes and not active at any time. Poor sleep quality was alarmingly highly prevalent among secondary school students, with significant health consequences. Increasing the awareness of the community especially adolescents, parents, and school teachers about healthy sleep is an essential priority.

Keywords: sleep quality, correlates, secondary schools

\section{Introduction}

Sleep is a physiological process that is essential for human life, especially during adolescence, which is a critical period for normal growth and development (Brand \& Kirov, 2011). It is a reversible state of behavioral unresponsiveness followed by a sense of revitalization and alertness (Orr, 2000). Sleep consists of two components, quantitative and qualitative; the quantitative component includes sleep

Please address queries to: Dalia G. Mahran, Public Health and Community Medicine, Faculty of Medicine, Assiut University. Email: daliaym2001@yahoo.com

The authors would like to acknowledge Salma Mohamed and Asmaa for helping in data collection and ministry of education, schools managers, and teachers who facilitate data collection at the selected schools. We deeply acknowledge the study participant students. 
duration and sleep latency, while the qualitative component is a subjective measure of the depth of sleep and feeling restful upon awakening (Buysse, Reynolds, Monk, Berman, \& Kupfer, 1989). Poor sleep can arise as a consequence of a number of problems, including difficulty falling or staying asleep, falling asleep at inappropriate times, long total sleep time, or abnormal behaviors related to sleep (Zhou et al., 2012). Marked sleep changes that occur during adolescence include getting up earlier, going to bed later, insufficient sleep, irregular sleep patterns, and increased daytime sleepiness (Liu, Zhao, Jia, \& Buysse, 2008).

Many studies done in Arab countries, such as Saudi Arabia (Al-Hazzaa, Musaiger, Abahussain, AlSobayel, \& Qahwaji, 2012; Merdad, Merdad, Nassif, El-Derwi, \& Wali, 2014), Oman (Kilani, AlHazzaa, Waly, \& Musaiger, 2013), Lebanon (Assaad, Costanian, Haddad, \& Tannous, 2014), and Jordan (Suleiman et al., 2013), have found the prevalence of short sleep duration or poor sleep quality using Pittsburgh Sleep Quality Index (PSQI) among secondary school or university student exceeding 50\%. The same prevalence was found in Ethiopia (Lemma, Gelaye, Berhane, Worku, \& Williams, 2012), United States (Lund, Reider, Whiting, \& Prichard, 2010), and Iran (Keshavarz Akhlaghi \& Ghalebandi, 2009).

Reduction in sleep duration and sleep quality across populations has been linked to increased work and social demands, changes in lifestyle, increasing use of technology, smoking, alcohol, current sexual activity, caffeine intake, dietary factors and level of physical activity (Al-Hazzaa et al., 2012; Calamaro, Mason, \& Ratcliffe, 2009; Chokroverty, 2009; McKnight-Eily et al., 2011; Van den Bulck, 2003, 2004; Zhou et al., 2012). Studies suggest sleep not only plays a key role in the physical growth of adolescents but also is highly important for behavioral and emotional development, learning, attention, and cognitive functioning (Friedman, Corley, Hewitt, \& Wright, 2009; Snell, Adam, \& Duncan, 2007). The way adolescents sleep and their tendency to get insufficient sleep make them vulnerable to negative effects on their mood and behavior (Lemma et al., 2012), ability to think and concentrate in school, and school performance (Dewald, Meijer, Oort, Kerkhof, \& Bögels, 2010). There is also an increased risk for injuries and accidents (Komada, Asaoka, Abe, \& Inoue, 2013), drugs and alcohol use (Passarella \& Duong, 2008), slow body metabolism and obesity (Garaulet et al., 2011), and circadian sleep disorders (Zhou et al., 2012).

There appear to be no studies that determine sleep patterns and correlated factors in secondary school students in Egypt. There are differences of prevalence of sleep problems between countries, which are based on ethnic and cultural beliefs (Sweileh et al., 2011).This study aims to determine the prevalence of poor sleep quality among secondary school students in the city of Assiut, Egypt, and to assess the psychological and general health correlates of poor sleep quality to fill this knowledge gap and provide basis for health development of adolescents in Egypt.

\section{Method}

\section{Sampling Procedure}

A cross-sectional study was conducted among the 7,686 students in their second year of secondary school. Calculation of the sample size was done per the equation for sample size of descriptive study design; we used the least prevalence from other studies of poor sleep quality in adolescents. The calculated number was 375 students. In this study, a multistage stratified random sampling technique was used to select the study sample to correct for the difference in design the sample size was multiplied by the design effect (2); the result equaled 750 . An increase in the sample by $5 \%$ is used to account for incomplete and nonresponders, but in our community, we experienced more dropout, so we increased it by $10 \%$. The final calculated sample was 825 students. 
The sample was selected by multistage stratified random sampling technique. The schools were stratified into public, private, and technical secondary schools, with further stratification into boys' and girls' schools. One school was randomly selected from each stratum, thereby giving a total of four girls' schools and four boys' schools; two schools were selected from public schools' strata to cover different locations in the city. Total sample size was divided proportionately per the number of students in the second year of secondary education in every school. Classes were selected using simple random sampling. All students in the selected classrooms were included. Only a few students refused the participation in the study.

\section{Measures}

A self-administered questionnaire was used in data collection. The data included the following: (a) demographic data of the students; (b) sleep quality, using the PSQI; (c) excessive daytime sleepiness, using the Epworth Sleepiness Scale; (d) general perception of health; and (e) psychological health: depression and anxiety symptoms were measured guided by the short form of Depression Anxiety and Stress Scale.

The demographic variables were categorized as follows: sex (male and female), residence (rural and urban), type of education (public, private, and technical), smoking (nonsmoker, smoker, and exsmoker) and parent education (illiterate, read and write, primary, preparatory, secondary, and high school education).

The PSQI is a self-administered questionnaire that is frequently used to assess sleep quality over the last month; it is a validated instrument that has been used to assess sleep quality of adolescents and young adults. It consists of 19 self-rated questions that evaluate factors related to sleep quality. These factors are grouped into seven component scores, all of which have equal weight on a $0-3$ scale. These components are sleep latency, subjective sleep quality, sleep duration, habitual sleep efficiency, sleep disturbances, daytime dysfunction, and use of sleep medication. All component scores are summed to give a global PSQI score from 0 to 21; a higher score indicates worse sleep quality. A global score greater than 5 is diagnostic for sleep disorders, and differentiates between people with good and bad sleep quality, with a sensitivity of $89.6 \%$ and specificity of $86.5 \%$.The internal consistency of the index (Cronbach's $\alpha=0.83$ ). The index requires 5 to $10 \mathrm{~min}$ to complete (Buysse et al., 1989). The questionnaire has been translated into Arabic by Suleiman et al. (2010).

The Epworth Sleepiness Scale is a validated questionnaire that asks for self-rated probability of dozing in eight different activities. The probability of dozing off (falling asleep) ranges from 0 (never doze) to 3 (high probability of dozing). A score higher than 10 indicates excessive daytime sleepiness. The scale has a high degree of internal consistency (Cronbach's $\alpha=0.88$; Johns, 1991).

The short form of the Depression Anxiety and Stress Scale consists of 21 questions-seven questions for each psychological morbidity. The questions ask about the experience of the items in the past week and each item is scored from 0 (did not apply to me at all) to 3 (applied to me very much). We used depression and anxiety components only to avoid elongation of the questionnaire that could lead to inaccurate data. Finally, the values obtained were multiplied by 2 . Cut-off points suggested in the literature were used to categorize the study participants according to symptom levels of depression and anxiety. The internal consistency has been reported as Cronbach's $\alpha=0.88$ for the depression scale and $\alpha=0.82$ for the anxiety scale (Henry \& Crawford, 2005). This scale was psychometrically validated to the Arabic culture by Taouk, Lovibond, and Laube (2001). 


\section{Procedures}

The pilot study was carried out on 40 students to determine administrative procedures needed for the research work, test the questionnaire form, detect any modification needed, and estimate the time needed to collect data, which was assessed as $30 \mathrm{~min}$. Only two questions were rephrased to be more easily understood by the students.

The proposal was approved by the Faculty Ethical Review Committee in our university before starting data collection. Approval was received from the Central Agency of Public Mobilization and Statistics and administration of secondary education and directors of every school. Informed consent was taken from every student after explanation of the aim and methodology of the study; parents' consent was not sought, as the questionnaire items did not include sensitive issues and it was not requested from the higher authorities. It was explained to the students that collected data are confidential and will be used for scientific research only.

Data collection was done at the middle of the first semester of academic year 2015-2016, away from the exam times. The questionnaire, which was explained page by page, was filled in by the students during class. Two well-trained data collectors and the class teacher helped the researcher to watch and keep understanding and completeness of data in every class during questionnaire completion.

\section{Data Analysis}

The study hypotheses follow.

Hypothesis 1: There would be a high prevalence of poor sleep quality among secondary school students in Egypt.

Hypothesis 2: Poor sleep quality would be associated with increased depression, anxiety symptoms, and poor general health.

Analyses included descriptive statistics (in the form of frequencies, means, and standard deviations [SDs] ) in addition to tests of significance such as the chi-square test for qualitative variables and Student's $t$ test and the Mann-Whitney $U$ test for quantitative variables. Binary logistic regression analysis was used to predict lifestyle factors that could be associated with poor sleep quality and health effects of poor sleep quality. Regression models were constructed including all significant factors that were found to be likely associated with poor sleep quality using bivariate analysis with only significant variables included in the final equation; $p$ value was considered significant when it was equal to or less than .05 .

\section{Results}

\section{Demographic Characteristics of the Participants}

The age of the 829 students ranged from 15 to 19 years, with a mean age of $16.66 \pm 0.72 S D$. More than half (54.9\%) were boys, $66.7 \%$ were from urban areas, $56.2 \%$ attended technical schools, $8.1 \%$ were smokers, $36 \%$ of participants' mothers were highly educated, and $42.8 \%$ of participants' fathers were highly educated. 


\section{Sleep Quality of the Participants and Its Correlates}

The prevalence of poor sleep among participants was 72.5\%, using the cut off of PSQI $>5$. The mean PSQI score was $7.35(S D=2.94)$. The percent of poor sleepers was significantly higher among females $(77.0 \%)$ than males (68.8\%). Urban residents (76.8\%) evidenced poorer sleep compared to rural residents (63.6\%). Poor sleepers were significantly higher among public school students (81.4\%) then private school students (76.9\%; Table 1$)$.

Table 1. Relationship Between Sociodemographic Characteristics and Sleep Quality Among Secondary School Students in Assiut, 2015

\begin{tabular}{|c|c|c|c|}
\hline Variables & $\begin{array}{l}\text { Good Sleepers } \\
\quad(n=228)\end{array}$ & $\begin{array}{l}\text { Poor Sleepers } \\
\quad(n=601)\end{array}$ & $p$ Value \\
\hline Age $M \pm S D(n=829)^{a}$ & $16.71 \pm 0.68$ & $16.64 \pm 0.73$ & \\
\hline Range & & 15 to 19 & \\
\hline \multicolumn{4}{|l|}{$\operatorname{Sex}(n=829)^{\mathrm{b}}$} \\
\hline Male & $142(31.2 \%)$ & $313(68.8 \%)$ & ** \\
\hline Female & $86(23.0 \%)$ & $288(77.0 \%)$ & \\
\hline \multicolumn{4}{|l|}{ Residence $(n=827)^{\mathrm{b}}$} \\
\hline Rural & $100(36.4 \%)$ & $175(63.6 \%)$ & \\
\hline Urban & $128(23.2 \%)$ & $424(76.8 \%)$ & $* * *$ \\
\hline \multicolumn{4}{|c|}{ Type of education $(n=829)^{\mathrm{b}}$} \\
\hline Public & $53(18.6 \%)$ & $232(81.4 \%)$ & $* * *$ \\
\hline Private & $18(23.1 \%)$ & $60(76.9 \%)$ & \\
\hline Technical & $157(33.7 \%)$ & $309(66.3 \%)$ & \\
\hline \multicolumn{4}{|l|}{ Smoking $(n=829)^{\mathrm{b}}$} \\
\hline Nonsmoker & $205(27.8 \%)$ & $532(72.2 \%)$ & \\
\hline Smoker & $15(22.4 \%)$ & $52(77.6 \%)$ & \\
\hline Ex-smoker & $8(32.0 \%)$ & $17(68.0 \%)$ & \\
\hline \multicolumn{4}{|c|}{ Mother education $(n=824)^{\mathrm{b}}$} \\
\hline Illiterate & $54(33.3 \%)$ & $108(66.7 \%)$ & \\
\hline Read and write & $19(23.8 \%)$ & $61(76.2 \%)$ & \\
\hline Primary & $15(24.2 \%)$ & $47(75.8 \%)$ & \\
\hline Preparatory & $18(40.0 \%)$ & $27(60.0 \%)$ & \\
\hline Secondary & $48(27.0 \%)$ & $130(73.0 \%)$ & \\
\hline High & $72(24.2 \%)$ & $225(75.8 \%)$ & \\
\hline \multicolumn{4}{|c|}{ Father education $(n=824)^{\mathrm{b}}$} \\
\hline Illiterate & $23(33.3 \%)$ & $46(66.7 \%)$ & \\
\hline Read and write & $15(24.2 \%)$ & $47(75.8 \%)$ & \\
\hline Primary & $15(32.6 \%)$ & $31(67.4 \%)$ & \\
\hline Preparatory & $20(39.2 \%)$ & $31(60.8 \%)$ & \\
\hline Secondary & $65(26.7 \%)$ & $178(73.3 \%)$ & \\
\hline High & $88(24.9 \%)$ & $265(75.1 \%)$ & \\
\hline
\end{tabular}

a Student's $t$ test was used. ${ }^{\mathrm{b}} \chi^{2}$ test was used.

${ }^{* *} p<.01 .{ }^{* * *} p<.001$. 
The percent of poor sleepers increased gradually from $61.5 \%$ in students with no depressive symptoms to $92.3 \%$ in students with severe to very severe depressive symptoms. In addition, the percent of poor sleepers increased gradually from $55.6 \%$ in students with no anxiety symptoms to $88.9 \%$ in students with severe to very severe anxiety symptoms. The majority of students (88.0\%) with excessive daytime sleepiness were poor sleepers with high significance compared to those students without excessive daytime sleepiness. A significant association between poor sleep and subjective health rating was found: $64.1 \%$ of those who rated their health "very good to excellent" were poor sleepers, which increased gradually to reach $88.6 \%$ among those who rated their health "bad to very bad." Among those who reported "feeling fully active" all the time, 58\% were poor sleepers, and this increased gradually to reach $90.7 \%$ among those did not report "feeling fully active" at any time. Poor sleep was also significantly associated with fatigue: $81.2 \%$ of those who reported "feeling fatigue" all the time were poor sleepers, with a gradual decline to reach $66.7 \%$ among those who didn't report "feeling fatigue" at any time (Table 2). As shown in Table 3, there was a statistically significant difference between means of students with poor sleep and students with good sleep in all PSQI categories, with higher means among poor sleepers.

The results of the multivariate logistic regression also show the following factors to be significant predictors of poor sleep. There is a likely $1.4 \times$ increase in the chance of poor sleep with every year increase in the students' ages [odds ratio $(O R)=1.428,95 \%$ confidence interval (CI) $[1.076,1.895]$ ). Poor sleepers from urban areas have a likely double increase in the risk than those from rural areas $(O R=1.992,95 \%$ CI [1.292, 3.072]). Students from public schools have a likely $1.8 \times$ increase in the chance to have poor sleep than those from technical schools $(O R=1.767,95 \%$ CI $[1.081,2.889])$. The chance of poor sleep is likely increased $2.3 \times$ and $4.9 \times$, respectively, with anxiety symptoms among those with mild to moderate and severe to very severe levels $(O R=2.308,95 \%$ CI $[1.551,3.434])$ compared to normal $(O R=4.858,95 \%$ CI $[2.866,8.232])$. The chance of poor sleep is likely increased $3.6 \times$ among those with severe to very severe depressive symptoms compared to normal $[O R=3.613$, 95\% CI [1.903, 6.862]). Excessive daytime sleepiness was associated with poor sleep quality; those who reported excessive daytime sleepiness were twice as likely to have poor sleep as normal students $(O R=2.023,95 \%$ CI $[1.170,3.496])$. The students who feel fully active sometimes $(O R=2.453,95 \%$ CI $[1.385,4.345])$ or do not feel active at any time $(O R=5.205,95 \%$ CI $[1.662,16.298])$ are likely have a $2.5 \times$ and $5.2 \times$ increased chance of poor sleep, respectively, compared to those feeling fully active all the time (Table 4$)$. 
Table 2. Relationship of Psychological and General Health Perception With Sleep Quality Among Secondary School Students in Assiut, 2015

\begin{tabular}{|c|c|c|c|}
\hline Variables & $\begin{array}{l}\text { Good Sleepers } \\
\quad(n=228)\end{array}$ & $\begin{array}{l}\text { Poor Sleepers } \\
\quad(n=601)\end{array}$ & $p$ Value \\
\hline \multicolumn{4}{|l|}{ Depression symptoms (using } \\
\hline \multicolumn{4}{|l|}{ DASS 21) $(n=829)$} \\
\hline Normal & $70(38.5 \%)$ & $112(61.5 \%)$ & \multirow{3}{*}{$* * *$} \\
\hline Mild to moderate & $140(34.0 \%)$ & $272(66.0 \%)$ & \\
\hline Severe to very severe & $18(7.7 \%)$ & $217(92.3 \%)$ & \\
\hline \multirow{2}{*}{\multicolumn{4}{|c|}{$\begin{array}{l}\text { Anxiety symptoms } \\
\text { (using DASS } 21 ; n=829 \text { ) }\end{array}$}} \\
\hline & & & \\
\hline Normal & $118(44.4 \%)$ & $148(55.6 \%)$ & \multirow[t]{3}{*}{$* * * *$} \\
\hline Mild to moderate & $81(26.9 \%)$ & $220(73.1 \%)$ & \\
\hline Severe to very severe & $29(11.1 \%)$ & $233(88.9 \%)$ & \\
\hline \multicolumn{4}{|l|}{$\begin{array}{l}\text { Daytime sleepiness (using ESS)a } \\
(n=829)\end{array}$} \\
\hline Normal & $208(31.4 \%)$ & $454(68.6 \%)$ & \multirow[t]{2}{*}{$* * * *$} \\
\hline Excessive daytime sleepiness & $20(12.0 \%)$ & $147(88.0 \%)$ & \\
\hline \multicolumn{4}{|l|}{ Subjective health rating $(n=829)$} \\
\hline Very good to excellent & $146(35.9 \%)$ & $261(64.1 \%)$ & \multirow[t]{3}{*}{$* * * *$} \\
\hline Good & $69(22.4 \%)$ & $239(77.6 \%)$ & \\
\hline Bad to very bad & $13(11.4 \%)$ & $101(88.6 \%)$ & \\
\hline \multicolumn{4}{|l|}{ Increased infection rate $(n=829)$} \\
\hline Strongly agree & $48(30.2 \%)$ & $111(69.8 \%)$ & \\
\hline Agree & $79(25.2 \%)$ & $235(74.8 \%)$ & \\
\hline Disagree & $38(22.4 \%)$ & $132(77.6 \%)$ & \\
\hline Strongly disagree & $63(33.9 \%)$ & $123(66.1 \%)$ & \\
\hline \multicolumn{4}{|l|}{ Feel fully active $(n=829)$} \\
\hline All of the time & $34(42 \%)$ & $47(58 \%)$ & \multirow[t]{4}{*}{$* * *$} \\
\hline Most of the time & $98(33.9 \%)$ & $191(66.1 \%)$ & \\
\hline Sometimes & $91(22.5 \%)$ & $314(77.5 \%)$ & \\
\hline None of the time & $5(9.3 \%)$ & $49(90.7 \%)$ & \\
\hline \multicolumn{4}{|l|}{ Feel fatigue $(n=829)$} \\
\hline All of the time & $15(18.8 \%)$ & $65(81.2 \%)$ & \multirow[t]{4}{*}{ ** } \\
\hline Most of the time & $66(21.8 \%)$ & $237(78.2 \%)$ & \\
\hline Sometimes & $129(32.9 \%)$ & $263(67.1 \%)$ & \\
\hline None of the time & $18(33.3 \%)$ & $36(66.7 \%)$ & \\
\hline Total & $228(27.5 \%)$ & $601(72.5 \%)$ & 829 \\
\hline
\end{tabular}

Note. DASS 21 = Depression Anxiety Stress Scale short form; ESS $=$ Epworth Sleepiness Scale.

${ }^{\text {a }} \chi^{2}$ test was used.

${ }^{* * *} p<.01 .{ }^{* * *} p<.001$. 
Table 3. Comparisons of $\mathrm{M} \pm$ SD of PSQI Components Between Poor Sleepers and Good Sleepers

\begin{tabular}{lccc} 
Variable & $\begin{array}{c}\text { Good Sleepers } \\
(n=228)\end{array}$ & $\begin{array}{c}\text { Bad Sleepers } \\
(n=601)\end{array}$ & $p$ Value \\
\hline Sleep duration & $1.06 \pm 0.96$ & $1.94 \pm 0.89$ & $* * *$ \\
Sleep latency & $0.57 \pm 0.64$ & $1.59 \pm 0.83$ & $* * *$ \\
Subjective sleep quality $^{*}$ & $0.54 \pm 0.62$ & $1.43 \pm 0.88$ & $* * *$ \\
Habitual sleep efficiency $^{\mathrm{b}}$ & $0.04 \pm 0.2$ & $0.42 \pm 0.77$ & $* * *$ \\
Using sleep medication $^{* * *}$ & $0.02 \pm 0.15$ & $0.2 \pm 0.63$ & ${ }^{* * *}$ \\
Daytime dysfunction & $0.67 \pm 0.63$ & $1.4 \pm 0.82$ & ${ }^{* * *}$ \\
Sleep disturbances & $1.16 \pm 0.50$ & $1.63 \pm 0.61$ & ${ }^{* * *}$ \\
Global PSQIc & $4.06 \pm 1.03$ & $8.6 \pm 2.42$ & $* * *$ \\
\hline
\end{tabular}

Note. PSQI = Global Pittsburgh Sleep Quality Index. Mann-Whitney $U$ test was used.

a Time taken to fall asleep. ${ }^{\mathrm{b}}$ Number of hours slept divided by number of hours spent in bed multiplied to 100.

c Each component has score from 0 to 3.

${ }^{* * *} p<.001$.

Table 4. Predictors of Poor Sleep Quality Among Secondary School Students in Assiut, 2015, Identified by Multivariate Logistic Regression Analysis

\begin{tabular}{|c|c|c|c|}
\hline Variable & $p$ Value & Odds Ratio & $\begin{array}{l}\text { 95\% Confidence } \\
\text { Interval }\end{array}$ \\
\hline Age & * & 1.428 & {$[1.076,1.895]$} \\
\hline Sex (female) & & 0.935 & {$[0.636,1.374]$} \\
\hline Residence (urban) & $* *$ & 1.992 & {$[1.292,3.072]$} \\
\hline \multicolumn{4}{|l|}{ Type of education } \\
\hline Public & * & 1.767 & {$[1.081,2.889]$} \\
\hline Private & & 1.477 & {$[0.729,2.992]$} \\
\hline \multicolumn{4}{|l|}{ Technical (reference) } \\
\hline \multicolumn{4}{|l|}{ Normal (reference) } \\
\hline Mild to moderate & $* * *$ & 2.308 & {$[1.551,3.434]$} \\
\hline Severe to very severe & **** & 4.858 & {$[2.866,8.232]$} \\
\hline \multicolumn{4}{|l|}{ Normal (reference) } \\
\hline Mild to moderate & & 0.914 & {$[0.605,1.381]$} \\
\hline Severe to very severe & **** & 3.613 & {$[1.903,6.862]$} \\
\hline \multicolumn{4}{|l|}{ Daytime sleepiness } \\
\hline $\begin{array}{l}\text { Excessive daytime } \\
\text { sleepiness }\end{array}$ & * & 2.023 & {$[1.170,3.496]$} \\
\hline $\begin{array}{l}\text { Feeling fully active } \\
\text { All of the time } \\
\text { (reference) }\end{array}$ & ** & & \\
\hline Most of the time & & 1.712 & {$[0.969,3.025]$} \\
\hline Sometimes & $* *$ & 2.453 & {$[1.385,4.345]$} \\
\hline None of the time & $* *$ & 5.205 & {$[1.662,16.298]$} \\
\hline
\end{tabular}

Note. Odds ratio is adjusted for all variables in the table.

$* p<.05 .{ }^{* *} p<.01 .{ }^{* * *} p<.001$. 


\section{Discussion}

This study investigated the sleep quality among secondary school students in Assiut and the likely associated results of poor sleep quality on adolescents' general perception of health and some psychological health aspects. Sleep disturbance associated problems in those adolescents were found.

\section{Prevalence of Poor Sleep Quality}

The current study found that $72.5 \%$ of the studied students were poor sleepers (global score of PSQI $>5$ ); this percent is higher than the findings from many countries. For example, poor sleepers were $65 \%$ of the participants in a study on 947 high school students aged 14-23 years in Jeddah, Saudi Arabia (Merdad et al., 2014). In Lebanon, 52\% of 735 students aged 18-25 years enrolled across six universities were poor sleepers (Assaad et al., 2014). In Los Angeles, California, $64 \%$ of 131 high school students aged 13-18 years were poor sleepers (Megdal \& Schernhammer, 2007). A similar prevalence of poor sleep was found in Ethiopia, with 55.8\% of 2,551 university students aged 17-35 years (median 21 years; Lemma et al., 2012), and in Iran, with $56 \%$ of 943 preuniversity students aged 18 years (Keshavarz Akhlaghi \& Ghalebandi, 2009). The lower prevalence of poor sleep quality in these studies may be due to extension of the age to include other age groups that are less subjected to sleep problems and different lifestyle characters in different countries. On the other hand, a higher percent of poor sleepers in Jordan ( $85 \%$ of 118 of nursing college students) could be due to more exposure to sleep disturbances, as medical and nursing students woke up earlier (as they are required to attend early morning clinical courses) and had shorter sleep time and more daytime dysfunction to meet the demands of their studies compared to other groups of students (Suleiman et al., 2013). Also, the differences of prevalence of sleep problems among countries may be a result of ethnic and cultural beliefs (Sweileh et al., 2011).

\section{Demographic Characteristics Associated With Sleep Quality}

In the current study, poor sleep quality was associated with females only in the bivariate analysis. This may be because females are more subject to anxiety, depression, and long periods of thinking (Voderholzer, Al-Shajlawi, Weske, Feige, \& Riemann, 2003). This is consistent with the results of many studies in different countries. In Jeddah, Merdad et al. (2014) found that females had significantly higher global PSQI scores than males in a study of 947 high school students aged 14-23 years. A study in Hong Kong found the same results (Chung \& Cheung, 2008). In another study in Japan, it was also reported that female adolescents had shorter sleep duration than males, and more female adolescents rated their sleep quality as poor or very poor (Munezawa et al., 2011).

In the current study, the prevalence rate of poor sleep quality was higher among residents of urban areas; this result is comparable to the results of a study of 1,056 high school students in China that found that urban students go to bed later than rural students (Liu et al., 2008). This is also consistent with the findings reported in another Chinese study that rural residents were more likely to report good levels of sleep quality compared to urban residents in middle-aged and elderly Chinese (Haseli-Mashhadi et al., 2009).

\section{Psychological and General Health Correlates of Poor Sleep Quality}

The present study found a statistically significant association between poor sleep quality and the reporting of depressive symptoms. This is consistent with other studies in Saudi Arabia (Abdallah \& Gabr, 2014), Ethiopia (Lemma et al., 2012), United States (Patten, Choi, Gillin, \& Pierce, 2000), Australia (Short, Gradisar, Lack, \& Wright, 2013), and Japan (Kaneita et al., 2009). 
The current study found a statistically significant association between poor sleep quality and reported anxiety symptoms. This association is consistent with the results of studies in Ethiopia (Lemma et al., 2012); Menoufiya, Egypt (Abdallah and Gabr, 2014); Estonia (Eller, Aluoja, Vasar, \& Veldi, 2006); and in an urban Midwestern university in Arizona (Lund et al., 2010).

In the current study, there was a statistically significant association between sleep quality and excessive daytime sleepiness. This association was found also in a Saudi study, which reported on respondents with poor quality of sleep (PSQI >5); Fatani et al., 2015). Also, short sleep duration was correlated with daytime sleepiness in Chinese children (Liu, Liu, Owens, \& Kaplan, 2005). Among high school students in Korea, students with excessive daytime sleepiness had a significantly higher prevalence of insomnia, habitual snoring, nightmares, witnessed apnea, and teeth grinding compared with students without excessive daytime sleepiness (Joo et al., 2005).

A better health rating and higher frequency of feeling fully active were significantly reported by good sleepers, while feeling fatigue most of the time was significantly reported by poor sleepers. These relations were consistent with the results of many studies, such as the study among Chinese adolescents that found better self-rated health significantly correlated with poor sleep quality $(r=$ -0.344; Xu et al., 2012). Another study with Midwestern University students found that participants categorized as poor sleepers (PSQI scores $\geq 8$ ) had a significantly higher fatigue score compared to good sleepers (Lund et al., 2010). Also, Noland, Price, Dake, and Telljohann (2009) reported tiredness most of the day in the majority of participants who didn't get enough sleep (93.7\%).

The current study was limited by being a cross-sectional study; because the temporal sequence was not clear, we could not judge the causal relation between the outcome and predictors. The results depend on self-reported data that is subjected to reporting bias. The study did not cover some aspects related to sleep—such as academic performance; stress; or sleep habits during exam times, weekends, and holidays - to avoid more elongation of the questionnaire, which could lead to inaccurate data. These factors need to be assessed in future studies.

Poor sleep quality should be considered a very serious medical problem, especially in adolescents and young adults. Its prevention should begin as early as possible. To improve sleep quality among adolescents, it is recommended that parents, teachers, and adolescents increase their awareness about healthy sleep patterns, sleep needs, and consequences of poor sleep. This could be done through mass media and school-based education programs.

\section{References}

Abdallah, A. R., \& Gabr, H. M. (2014). Depression, anxiety and stress among first year medical students in an Egyptian public university. International Research Journal of Medicine and Medical Sciences, 2, 11-19.

Al-Hazzaa, H. M., Musaiger, A. O., Abahussain, N. A., Al-Sobayel, H. I., \& Qahwaji, D. M. (2012). Prevalence of short sleep duration and its association with obesity among adolescents 15-to 19-year olds: A cross-sectional study from three major cities in Saudi Arabia. Annals of Thoracic Medicine, 7, 133-139.

Assaad, S., Costanian, C., Haddad, G., \& Tannous, F. (2014). Sleep patterns and disorders among university students in Lebanon. Journal of Research in Health Sciences, 14, 198-204.

Brand, S., \& Kirov, R. (2011). Sleep and its importance in adolescence and in common adolescent somatic and psychiatric conditions. International Journal of General Medicine, 4, 425-442. 
Buysse, D. J., Reynolds, C. F., Monk, T. H., Berman, S. R., \& Kupfer, D. J. (1989). The Pittsburgh Sleep Quality Index: A new instrument for psychiatric practice and research. Psychiatry Research, 28, 193-213. doi: 10.1016/0165-1781(89)90047-4

Calamaro, C. J., Mason, T. B., \& Ratcliffe, S. J. (2009). Adolescents living the 24/7 lifestyle: Effects of caffeine and technology on sleep duration and daytime functioning. Pediatrics, 123, 10051010 .

Chokroverty, S. (2009). Sleep disorders medicine: Basic science, technical considerations, and clinical aspects (3rd edition). Philadelphia, PA: Saunders Elsevier.

Chung, K.-F., \& Cheung, M.-M. (2008). Sleep-wake patterns and sleep disturbance among Hong Kong Chinese adolescents. Sleep, 31, 185-194.

Dewald, J. F., Meijer, A. M., Oort, F. J., Kerkhof, G. A., \& Bögels, S. M. (2010). The influence of sleep quality, sleep duration and sleepiness on school performance in children and adolescents: A meta-analytic review. Sleep Medicine Reviews, 14, 179-189.

Eller, T., Aluoja, A., Vasar, V., \& Veldi, M. (2006). Symptoms of anxiety and depression in Estonian medical students with sleep problems. Depression and Anxiety, 23, 250-256.

Fatani, A., Al-Rouqi, K., Al Towairky, J., Ahmed, A. E., Al-Jahdali, S., Ali, Y., Khan, M. (2015). Effect of age and gender in the prevalence of excessive daytime sleepiness among a sample of the Saudi population. Journal of Epidemiology and Global Health, 5, S59-S66.

Friedman, N. P., Corley, R. P., Hewitt, J. K., \& Wright, K. P. (2009). Individual differences in childhood sleep problems predict later cognitive executive control. Sleep, 32, 323-333.

Garaulet, M., Ortega, F., Ruiz, J., Rey-Lopez, J., Beghin, L., Manios, Y., \& Kafatos, A. (2011). Short sleep duration is associated with increased obesity markers in European adolescents: Effect of physical activity and dietary habits: The HELENA study. International Journal of Obesity, $35,1308-1317$.

Haseli-Mashhadi, N., Dadd, T., Pan, A., Yu, Z., Lin, X., \& Franco, O. H. (2009). Sleep quality in middle-aged and elderly Chinese: Distribution, associated factors and associations with cardio-metabolic risk factors. BMC Public Health, 9, 130.

Henry, J. D., \& Crawford, J. R. (2005). The short-form version of the Depression Anxiety Stress Scales (DASS-21): Construct validity and normative data in a large non-clinical sample. British Journal of Clinical Psychology, 44, 227-239.

Johns, M. W. (1991). A new method for measuring daytime sleepiness: the Epworth sleepiness scale. Sleep, 14, 540-545.

Joo, S., Shin, C., Kim, J., Yi, H., Ahn, Y., Park, M., . . Lee, S. (2005). Prevalence and correlates of excessive daytime sleepiness in high school students in Korea. Psychiatry and Clinical Neurosciences, 59, 433-440.

Kaneita, Y., Yokoyama, E., Harano, S., Tamaki, T., Suzuki, H., Munezawa, T., .. . Ohida, T. (2009). Associations between sleep disturbance and mental health status: A longitudinal study of Japanese junior high school students. Sleep Medicine, 10, 780-786.

Keshavarz Akhlaghi, A.-A., \& Ghalebandi, M. F. (2009). Sleep quality and its correlation with general health in pre-university students of Karaj, Iran. Iranian Journal of Psychiatry and Behavioral Sciences, 3, 44-49. 
Kilani, H., Al-Hazzaa, H., Waly, M. I., \& Musaiger, A. (2013). Lifestyle habits: Diet, physical activity and sleep duration among Omani adolescents. Sultan Qaboos University Medical Journal, $13,510-519$.

Komada, Y., Asaoka, S., Abe, T., \& Inoue, Y. (2013). Short sleep duration, sleep disorders, and traffic accidents. IATSS Research, 37, 1-7. doi: http://dx.doi.org/10.1016/j.iatssr.2013.06.001

Lemma, S., Gelaye, B., Berhane, Y., Worku, A., \& Williams, M. A. (2012). Sleep quality and its psychological correlates among university students in Ethiopia: A cross-sectional study. BMC Psychiatry, 12, 237.

Liu, X., Liu, L., Owens, J. A., \& Kaplan, D. L. (2005). Sleep patterns and sleep problems among schoolchildren in the United States and China. Pediatrics, 115, 241-249.

Liu, X., Zhao, Z., Jia, C., \& Buysse, D. J. (2008). Sleep patterns and problems among Chinese adolescents. Pediatrics, 121, 1165-1173.

Lund, H. G., Reider, B. D., Whiting, A. B., \& Prichard, J. R. (2010). Sleep patterns and predictors of disturbed sleep in a large population of college students. Journal of Adolescent Health, 46, 124-132. doi: http://dx.doi.org/10.1016/j.jadohealth.2009.06.016

McKnight-Eily, L. R., Eaton, D. K., Lowry, R., Croft, J. B., Presley-Cantrell, L., \& Perry, G. S. (2011). Relationships between hours of sleep and health-risk behaviors in U.S. adolescent students. Preventive Medicine, 53, 271-273.

Megdal, S. P., \& Schernhammer, E. S. (2007). Correlates for poor sleepers in a Los Angeles high school. Sleep Medicine, 9, 60-63.

Merdad, R. A., Merdad, L. A., Nassif, R. A., El-Derwi, D., \& Wali, S. O. (2014). Sleep habits in adolescents of Saudi Arabia: Distinct patterns and extreme sleep schedules. Sleep Medicine, $15,1370-1378$.

Munezawa, T., Kaneita, Y., Osaki, Y., Kanda, H., Minowa, M., Suzuki, K., Ohida, T. (2011). The association between use of mobile phones after lights out and sleep disturbances among Japanese adolescents: A nationwide cross-sectional survey. Sleep, 34, 1013-1020.

Noland, H., Price, J. H., Dake, J., \& Telljohann, S. K. (2009). Adolescents' sleep behaviors and perceptions of sleep. Journal of School Health, 79, 224-230.

Orr, W. C. (2000). Sleep and functional bowel disorders: Can bad bowels cause bad dreams? The American Journal of Gastroenterology, 95, 1118-1121.

Passarella, S., \& Duong, M.-T. (2008). Diagnosis and treatment of insomnia. American Journal of Health-System Pharmacy, 65, 927-934.

Patten, C. A., Choi, W. S., Gillin, J. C., \& Pierce, J. P. (2000). Depressive symptoms and cigarette smoking predict development and persistence of sleep problems in U.S. adolescents. Pediatrics, 106, e23.

Short, M. A., Gradisar, M., Lack, L. C., \& Wright, H. R. (2013). The impact of sleep on adolescent depressed mood, alertness and academic performance. Journal of Adolescence, 36, 10251033 .

Snell, E. K., Adam, E. K., \& Duncan, G. J. (2007). Sleep and the body mass index and overweight status of children and adolescents. Child Development, 78, 309-323.

Suleiman, K. H., Yates, B. C., Berger, A. M., Pozehl, B., \& Meza, J. (2010). Translating the Pittsburgh sleep quality index into Arabic. Western Journal of Nursing Research, 32, 250268. 
Suleiman, K. H., Yates, B. C., Jassem, H., Alghabeesh, S., Abu-Shahroor, L., \& Ali, R. (2013). Sleep disturbances among Alzaytoonah university students in Jordan. Journal of Natural Sciences Research, 3, 39-46.

Sweileh, W. M., Ali, I. A., Sawalha, A. F., Abu-Taha, A. S., Sa'ed, H. Z., \& Al-Jabi, S. W. (2011). Sleep habits and sleep problems among Palestinian students. Child and Adolescent Psychiatry and Mental Health, 5, 25.

Taouk, M. M., Lovibond, P., \& Laube, R. (2001). Psychometric properties of an Arabic version of the Depression Anxiety Stress Scales (DASS21). (Report for New South Wales Transcultural Mental Health Centre). Sydney, New South Wales, Australia: Cumberland Hospital.

Van den Bulck, J. (2003). Text messaging as a cause of sleep interruption in adolescents, evidence from a cross-sectional study. Journal of Sleep Research, 12, 263.

Van den Bulck, J. (2004). Television viewing, computer game playing, and Internet use and selfreported time to bed and time out of bed in secondary-school children. Sleep, 27, 101-104.

Voderholzer, U., Al-Shajlawi, A., Weske, G., Feige, B., \& Riemann, D. (2003). Are there gender differences in objective and subjective sleep measures? A study of insomniacs and healthy controls. Depression and Anxiety, 17, 162-172.

Xu, Z., Su, H., Zou, Y., Chen, J., Wu, J., \& Chang, W. (2012). Sleep quality of Chinese adolescents: Distribution and its associated factors. Journal of Paediatrics and Child Health, 48, 138145.

Zhou, H. Q., Shi, W. B., Wang, X. F., Yao, M., Cheng, G. Y., Chen, P. Y., \& Li, D. G. (2012). An epidemiological study of sleep quality in adolescents in South China: A school-based study. Child: Care, Health and Development, 38, 581-587.

The Journal of Social, Behavioral, and Health Sciences is an open-access, peer-reviewed, online interdisciplinary journal focusing on research findings that address contemporary national and international issues. Its objectives are to (a) encourage dialogue between scholars and practitioners in the social, behavioral, and health sciences that fosters the integration of research with practice; (b) promote innovative models of interdisciplinary collaboration among the social, behavioral, and health sciences that address complex social problems; and (c) inform the relationship between practice and research in the social, behavioral, and health sciences.

Walden University Publishing: http://www.publishing.waldenu.edu 